Article

\title{
Directional Oxidation of Pyrite in Acid Solution
}

\author{
Jiling Feng ${ }^{1,2}$, Hua Tian ${ }^{1,2}$, Yaling Huang ${ }^{1,2}$, Zhiying Ding ${ }^{1,2, *}$ and Zhoulan Yin ${ }^{1,2}$ \\ 1 School of Chemistry and Chemical Engineering, Central South University, Changsha 410083, China; \\ fengjlcsu@163.com (J.F.); tianxlu@yeah.net (H.T.); yelinahuang@163.com (Y.H.); xhli@csu.edu.cn (Z.Y.) \\ 2 Hunan Provincial Key Laboratory of Efficient and Clean Utilization of Manganese Resources, \\ Central South University, Changsha 410083, China \\ * Correspondence: zy.ding@csu.edu.cn; Tel.: +86-731-88-879-616
}

Received: 31 October 2018; Accepted: 20 December 2018; Published: 22 December 2018

\begin{abstract}
This study aimed to investigate the oxidation mechanism of pyrite crystallographic direction by cutting pyrite samples to expose their (100), (110), and (111) planes. Differences in the oxidation rates of pyrite planes in acid solution were determined. The morphological changes of pyrite were evaluated by scanning electron microscopy and hyperdepth-3D microscopy. The oxidation products of pyrite were examined by Raman spectroscopy and X-ray photoelectron spectroscopy. Results showed that the aqueous oxidation of pyrite produced $\mathrm{Fe}(\mathrm{OH})_{3}, \mathrm{Fe}_{2} \mathrm{O}_{3}, \mathrm{Fe}_{2}\left(\mathrm{SO}_{4}\right)_{3}$, and $\mathrm{S}_{8}$ on the surface. Moreover, the morphologies of corrosion patterns differed from one crystal plane to another: square, rectangular, and triangular etch pits were found on the (100), (110), and (111) planes, respectively. The corrosion patterns reflected the symmetrical arrangement of the crystallographic planes in the lattice on which they formed.
\end{abstract}

Keywords: pyrite; crystallographic direction; oxidation; etch pits

\section{Introduction}

Pyrite, accompanied with other sulfide ores, is considered the most abundant metal sulfide in the Earth's crust and is frequently found in massive hydrothermal deposits, igneous rocks, and sedimentary beds [1-3]. Natural pyrite contains many heavy metals, such as $\mathrm{Ag}, \mathrm{Au}, \mathrm{Cd}, \mathrm{Co}, \mathrm{Cu}, \mathrm{Mo}, \mathrm{Ni}, \mathrm{Pb}, \mathrm{Se}$, $\mathrm{Sb}, \mathrm{Sn}, \mathrm{Te}$, and $\mathrm{Zn}[4]$. Thus, pyrite oxidation usually releases many heavy-metal ions. Furthermore, pyrite oxidation involves water and oxygen consumption, in which sulfuric acid forms and acid mine (or acid rock) drainage (AMD or ARD) subsequently occurs. AMD or ARD has become a long-term environmental problem, affecting the ecological environment through the dissolution of rocks, acidification of aquifers, and mobilization of heavy metals. Pyrite oxidation has attracted considerable attention in the past decades [5-10]. For example, surface oxidation of pyrite aids in the extraction of valuable metals from pyrite deposits. Meanwhile, pyrite oxidation in acid solutions, which is the main source of AMD, should be investigated. However, the oxidation mechanism of pyrite remains unclear. The reported results and conclusions do not conform with oxidation mechanism and kinetics [11]. In general, several intermediate products, such as $\mathrm{S}_{2} \mathrm{O}_{3}{ }^{2-}, \mathrm{S}^{0}$, and $\mathrm{HSO}_{4}{ }^{-}$, are probably formed during pyrite oxidation [12-15]. $\mathrm{S}_{8}, \mathrm{Fe}_{2} \mathrm{O}_{3}$, and $\mathrm{Fe}(\mathrm{OH})_{3}$ are also found [16]. Accordingly, this study aimed to systematically investigate the surface oxidation of pyrite to understand its oxidation mechanism and to find means to reduce the source of AMD.

The crystal structure of pyrite resembles that of $\mathrm{NaCl}$. Pyrite belongs to the crystallographic space group Pa 3 [17]. Dumbbell-shaped disulfide ions $\left(\mathrm{S}_{2}{ }^{2-}\right)$ and $\mathrm{Fe}$ atoms occupy the $\mathrm{Cl}$ and Na positions, respectively. $\mathrm{S}_{2}{ }^{2-}$ is located at the center of the cubes and at the midpoints of the cube edges. Each $\mathrm{S}$ atom is coordinated with three Fe and another $\mathrm{S}$ atom, and each Fe atom bonds with six $\mathrm{S}$ atoms in a tilted octahedron [18]. Naturally-exposed crystal planes, such as cubic (100), octahedral (111), and pyritohedral (210) planes, are some low miller index facets [19]. Few studies have focused on 
crystal direction properties during pyrite oxidation. Sit et al. [20] investigated the interaction of pyrite (100) plane with water and oxygen molecules by using density functional theory (DFT). Zhu et al. [21] evaluated the oxidation behavior of naturally existing (100), (111), and (210) planes by conducting DFT calculations. All these studies provide detailed information about the atomic structure of crystal directions and some possibilities in investigating the surface changes during pyrite oxidation.

In the present work, the directional oxidation rate and morphologies of pyrite surface were investigated. Raman spectroscopy and X-ray photoelectron spectroscopy (XPS) were used to detect the surface oxidation products. The results on surface morphology can provide a complete understanding of pyrite oxidation.

\section{Sample and Methods}

\subsection{Sample Preparation}

Lump pyrite samples with approximately $1 \mathrm{~cm}^{3}$ and $4-6 \mathrm{~g}$ weight used in this study were natural cubic pyrite obtained from Hunan Province, China. The samples were cut by using a diamond saw parallel to the (100), (110), and (111) planes and were mounted with epoxy resin, where only the cut surfaces are exposed [22]. Before each experiment, the cut surfaces were polished with abrasive paper and diamond paste, washed with deionized water, and ultrasonically cleaned in ethanol for 30 min to remove any soluble impurities. The polished samples were placed in a glove box (Mikrouna Super 1220/750/900, Mikrouna, Shanghai, China) to avoid oxidation in air. The chemical composition of pyrite samples was analyzed by using an X-ray fluorescence (XRF, Shimadzu-1800, Shimadzu Corp., Kyoto, Japan) at $40 \mathrm{kV}$ and $95 \mathrm{~mA}$. The results listed in Table 1 show that the sample is a typical pyrite with $44.86 \%$ Fe and $44.06 \% \mathrm{~S}$, which slightly deviates from theoretical composition (Fe 46.6\%, S 53.4\%). The main impurities are $\mathrm{O}, \mathrm{Si}, \mathrm{Al}, \mathrm{K}, \mathrm{Ti}, \mathrm{Ca}, \mathrm{Zn}, \mathrm{Ru}$, and $\mathrm{Mg}$, all in trace amounts. The content of $\mathrm{O}$ accounting for $8.45 \%$ is the highest among the impurities, which may be due to the surface oxidation or $\mathrm{S}$ defect in the lattice.

Table 1. Chemical analysis for the pyrite sample.

\begin{tabular}{ccccccccccccccc}
\hline Element & $\mathbf{F e}$ & $\mathbf{S}$ & $\mathbf{O}$ & $\mathbf{S i}$ & $\mathbf{A l}$ & $\mathbf{K}$ & $\mathbf{T i}$ & $\mathbf{C a}$ & $\mathbf{Z n}$ & $\mathbf{R u}$ & $\mathbf{M g}$ & $\mathbf{P}$ & $\mathbf{N i}$ & $\mathbf{C r}$ \\
\hline Composition $(w \mathrm{t} \%)$ & 44.86 & 44.06 & 8.45 & 1.07 & 0.72 & 0.33 & 0.12 & 0.09 & 0.09 & 0.09 & 0.07 & 0.02 & 0.02 & 0.01 \\
\hline
\end{tabular}

\subsection{Experimental}

The matching surfaces of the (100), (110), and (111) planes were used in the experiments. Oxidation experiments in acid solution were conducted at room temperature. The pyrite sample was placed in an Erlenmeyer flask filled with $250 \mathrm{~mL}$ of $1 \mathrm{~mol} / \mathrm{L} \mathrm{H}_{2} \mathrm{SO}_{4}$ and $10 \mathrm{of} \mathrm{mL} 9.9 \mathrm{~mol} / \mathrm{L} \mathrm{H}_{2} \mathrm{O}_{2}$. The samples were removed and were washed with deionized water and ethanol at certain interval. After drying at room temperature, the morphology changes of samples were monitored by using a scanning electron microscopy (SEM) (Jeol JSM-6490LV, Jeol Ltd., Tokyo, Japan) at a resolution less than $3 \mathrm{~nm}(30 \mathrm{kV}$, high vacuum, tungsten filament, secondary electron). The surface element was analyzed by using an energy-dispersive spectrometer (EDS).

A hyperdepth-3D microscopy system (Keyence VHX-5000, Keyence, Osaka, Japan) was used to measure the depth and volume of etching pits on the pyrite surfaces under $500 \times$. The hyperdepth-3D microscopy system has a super high-resolution of $\mathrm{z}$ axis of $\pm 1 \mu \mathrm{m}$. Autofocus can be realized in $3 \mathrm{D}$ directions. The specific steps are expressed as follows: three to five different areas were selected for observation under the hyperdepth-3D microscopy system for each sample. A total of 5-8 etching pits were selected in each region, in which their depth and volume are measured, and their average values are obtained.

The concentration of the total $\mathrm{Fe}$ ions $\left(\mathrm{Fe}^{3+}\right.$ and $\left.\mathrm{Fe}^{2+}\right)$ was determined by using an inductively-coupled plasma optical emission spectrometer with a Perkin-Elmer Optima 5300 DV 
(Perkin-Elmer, Inc., Waltham, MA, USA). Plasma power was $1300 \mathrm{~W}$ by using CHNS mode and TCD detector.

Raman spectra data were recorded by using a Renishaw inVia (1800) instrument. The power of $\mathrm{He}-\mathrm{Ne}$ laser is $50 \mathrm{~mW}$, and laser wavelength is $532 \mathrm{~nm}$. The exposure time is $10 \mathrm{~s}$, which is cumulative three times. The analyzed surface size is approximately $2 \mathrm{~mm}$.

XPS (ESCALAB250Xi, ThermoFisher-VG Scientific, Waltham, MA, USA) analysis was conducted by using a Thermo Scientific Escalab-250 instrument. Al-K $\alpha$ X-ray $(1486.6 \mathrm{eV})$, which is used as the source of radiation, was operated at $150 \mathrm{~W}(15 \mathrm{kV}, 10 \mathrm{~mA})$ and irradiating spot size of $500 \mu \mathrm{m}$ on the pyrite surface. The depth of surface information is approximately $10 \mathrm{~nm}$. The best vacuum is greater than $5 \times 10^{-10}$ mbar at room temperature. The $C_{1 s}$ spectrum of peak at $284.8 \mathrm{eV}$ was used to correct the data. XPS data were fitted in XPSPEAK4.0 software.

\section{Result and Discussion}

\subsection{Pyrite Surface Characterization}

The morphology of freshly polished pyrite surface is shown in Figure 1. Generally, the surface of pyrite is smooth and flat. Several small black spots are occasionally observed, which are probably due to some impurities or defects on the pyrite surface. As shown in Figure 1, the element compositions of fresh pyrite surface are $\mathrm{Fe}(45.79 \%)$ and S (54.21\%) with high purity.

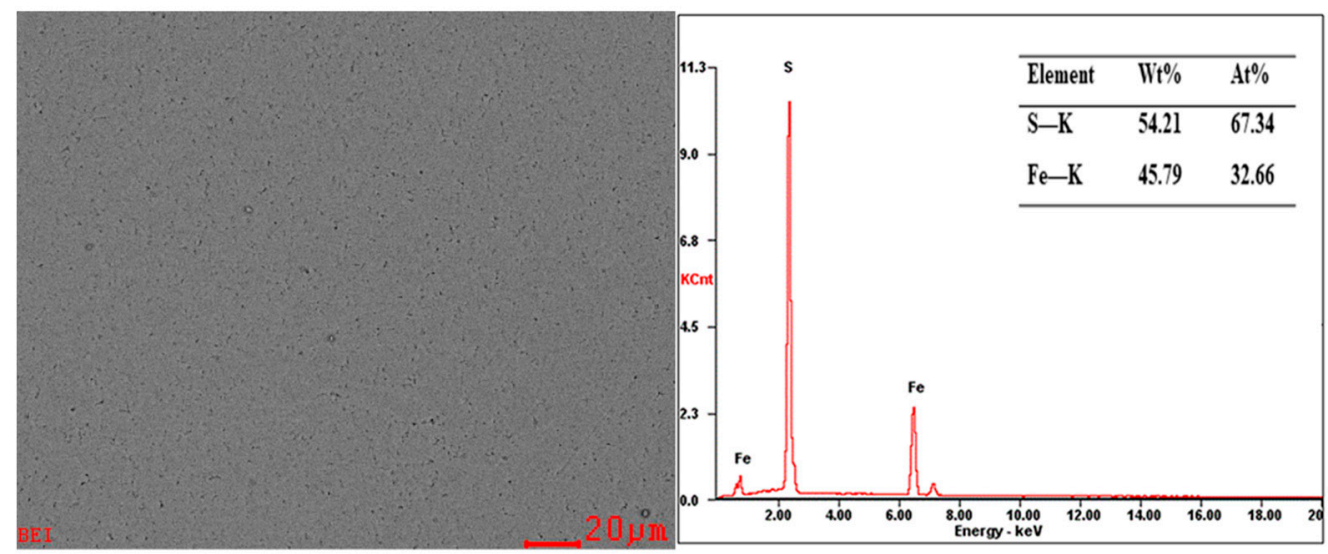

Figure 1. Electron microprobe characterization of a polished pyrite surface.

\subsection{Surface Topography Change}

Pyrite samples were removed from the reaction vessel after oxidation for four or eight days. Then, the corrosion patterns on the surfaces were observed. Different etching pits were observed on different crystal directions. Figure 2 shows the typical etching pits on the exposed (100), (110), and (111) pyrite surfaces after oxidation for four days. Figure 2a shows that the etching pits are generally square on the (100) plane. Rectangle patterns appear on the (110) plane, as shown in Figure 2b, and the etching pits on the (111) plane are triangular, as shown in Figure 2c. These etching pits usually aggregate together. The etching pits are obvious after oxidation for eight days, as shown in Figure 3 . The etching pits on the (110) plane are linked together to exhibit elongated pits. These etching pits reflect the symmetrical arrangement of crystallographic planes in the lattice. The point group of the crystal can be obtained when all etching pits on different directions of the same crystal are combined. The symmetries of the (100), (110), and (111) planes are $4 \mathrm{~mm}, 2 \mathrm{~mm}$, and $3 \mathrm{~mm}$, respectively. The etching pits in all directions have the same symmetry. The same results are found in olivine and quartz [23]. These results indicate that the corrosion patterns are closely related to the symmetry of the crystal structure. 


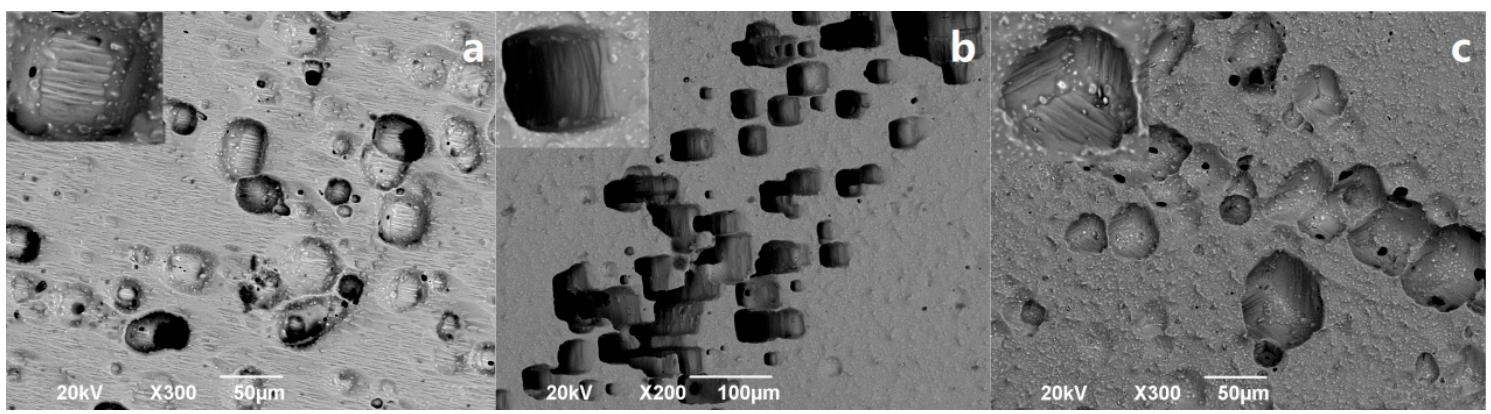

Figure 2. Corrosion patterns on different crystal directions after four days: (a) (100); (b) (110), and (c) (111).

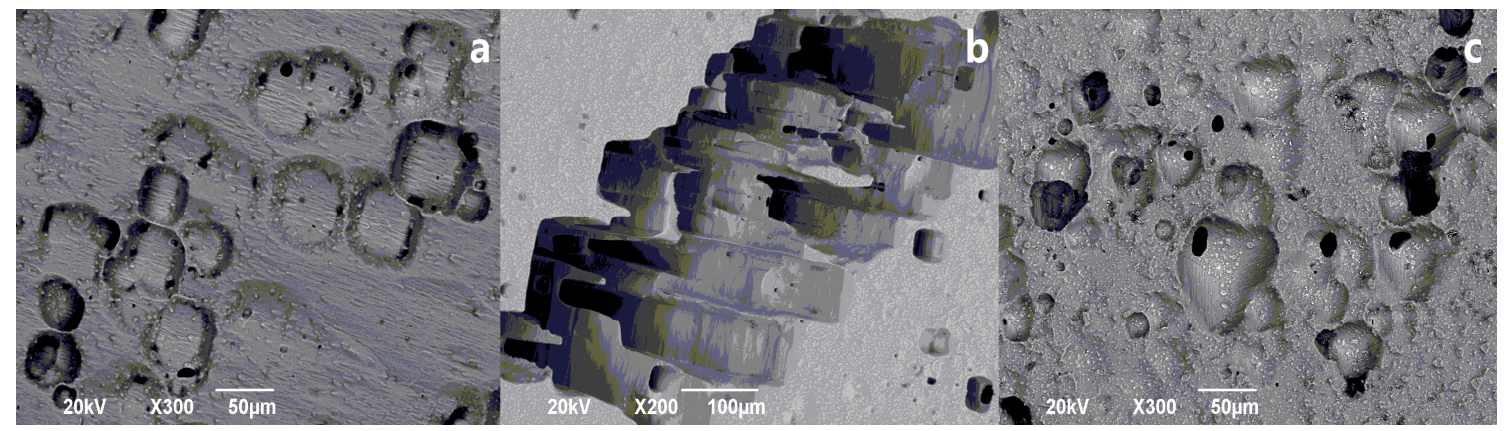

Figure 3. Corrosion patterns on different crystal directions after eight days: (a) (100); (b) (110), and (c) (111).

\subsection{Depth and Volume Analysis of Etching Pits}

Figure 4 a shows the depth changes of etching pits in different planes with time. As shown in Figure $4 a$, the depth of etching pits increases with time. The depth of etching pits on the (110) plane is larger than that on the (100) and (111) planes. However, the depth of etching pits cannot accurately reflect the oxidation rate because it is related to the density and size of the pits. Then, their volumes are investigated, where different crystal directions have different volumes, as shown in Figure $4 \mathrm{~b}$. The volume of etching pits on the (110) plane is the largest, and the volumes of (100) and (111) planes have a small difference. Moreover, the pits grow deep with a small number on the (110) plane. The pits on (100) and (111) planes are small and many.
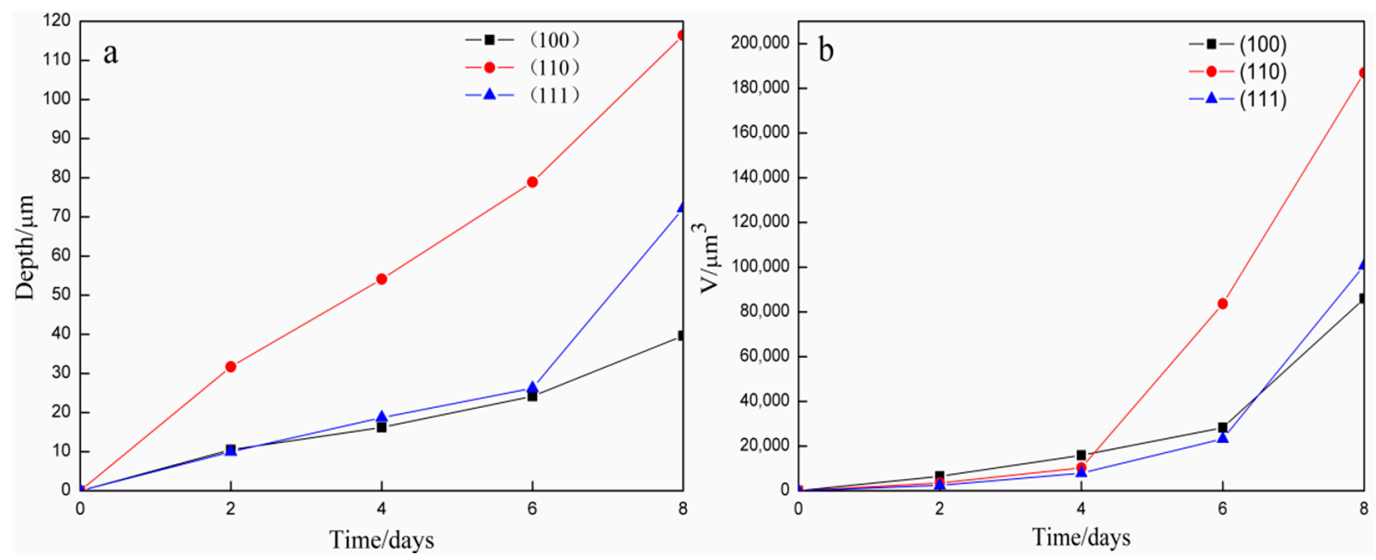

Figure 4. Crystal direction depth and volume changes of etching pits. (a) Depth changes, and (b) volume changes. 


\subsection{Fe Ion Concentration}

Considering the incomplete statistics of etching pits, the concentrations of "total iron" ion were measured in different crystal directions. Figure 5 shows the variation of the "total iron" concentration with time. This figure indicates that different oxidation rates are observed in different crystal directions. The (111) plane shows a higher oxidation rate compared with the (100) and (110) planes. The directional oxidation rate is $r_{(111)}>r_{(110)}>r_{(100)}$. This finding agrees with the results of Ndlovu and Monhemius [22] and is probably due to the difference in geometric arrangement of atoms in different crystal directions. The atomic arrangement of the pyrite (111) plane is -S-S-S-S- or $-\mathrm{Fe}-\mathrm{Fe}-\mathrm{Fe}-\mathrm{Fe}-$, and the (100) plane is $-\mathrm{Fe}-\mathrm{S}-\mathrm{S}-\mathrm{Fe}-$. The S-S bond in pyrite is weaker than that of the $\mathrm{Fe}-\mathrm{S}$ bond [24]. Therefore, the (100) plane is more stable. The results indicate that the surface atomic arrangement is important for the physical and chemical behavior of pyrite. Moreover, crystal growth theory (periodic bond chain (PBC) theory) describes that the morphology of crystals is obtained from the geometrical characteristics of the internal structure of crystals and the energy of particles. A PBC is an uninterrupted bond chain with periodic repetition of the strongest bond in a certain direction of crystallization. The plane refers to the F surface when more than two PBCs are parallel to a certain plane, in which its mesh is dense and flat and its growth rate is small. The plane refers to the $S$ surface when only one PBC is parallel to it, which has a small and few secondary directions on the crystal. This plane is also called the stepped face. The plane refers to the K surface when no PBC is parallel to it, which is also called the kinked face. Its growth rate is the fastest and easier to disappear [25]. In pyrite, the Fe-S bond is stronger than that of $\mathrm{S}-\mathrm{S}$ bond. Two periodic Fe-S bond chains are parallel to the (100) plane, which belong to the F surface and indicate its stable property. The (110) plane has one parallel PBC, which shows a fast oxidation rate. Meanwhile, the (111) plane without any parallel PBC exhibits a faster oxidation rate. This theory perfectly explains our experimental results.

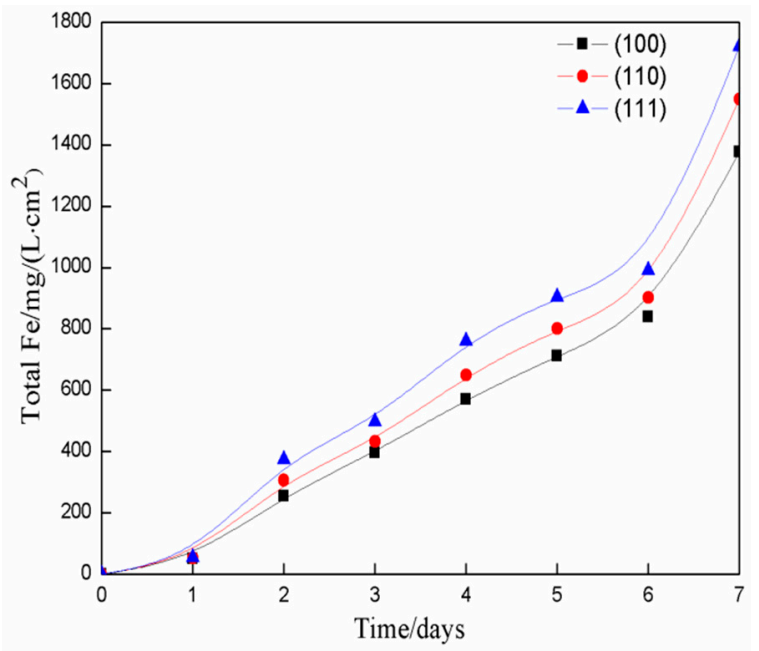

Figure 5. "Total iron" concentration in acid solution with time.

\subsection{Raman Spectra Analysis}

Raman spectra on different crystal directions of pyrite were measured before and after oxidation in acid solution to obtain the oxidation products of pyrite, as shown in Figure 6. Before oxidation, three peaks are found on the (100), (110), and (111) pyrite planes, which are located at 342,380 , and $430 \mathrm{~cm}^{-1}$, respectively. These peaks can be attributed to the deformation vibration of S-S and stretching vibration peak of Fe-S and S-S. New peaks appear or some peaks disappear after eight days. As shown in Figure $6 \mathrm{a}$, the stretching vibrational peaks of S-S disappear, and other products on the surface are not detected through Raman spectroscopy, which show that the S-Fe bond is more stable than that of the S-S bond. For the (110) plane in Figure $6 \mathrm{~b}$, new peaks at 226 and $410 \mathrm{~cm}^{-1}$ appear, which can be ascribed to $\mathrm{Fe}(\mathrm{OH})_{3}$. The weak peak at approximately $244 \mathrm{~cm}^{-1}$ belongs to the $\mathrm{Fe}-\mathrm{O}$ stretching 
vibrations of $\mathrm{Fe}(\mathrm{OH})_{3}$ or $\mathrm{S}$. The peak at $290 \mathrm{~cm}^{-1}$ is the symmetric stretching vibration of the $\mathrm{Fe}-\mathrm{O}$ bond of $\mathrm{Fe}_{2} \mathrm{O}_{3}$. The weak peak at $609 \mathrm{~cm}^{-1}$ is the bending vibration of the $\mathrm{Fe}-\mathrm{O}$ bond of $\mathrm{Fe}_{2} \mathrm{O}_{3}$ or $\mathrm{Fe}(\mathrm{OH})_{3}$. This spectrum shows that $\mathrm{Fe}_{2} \mathrm{O}_{3}$ and $\mathrm{Fe}(\mathrm{OH})_{3}$ are definitely formed on the pyrite surface, which agrees with the results of Tu et al. [16]. However, the peak of $S$ is not evident, which is probably because $S$ is oxidized to sulfate. The reaction equation is expressed as Equation (1)

$$
2 \mathrm{~S}^{0}+3 \mathrm{O}_{2}+2 \mathrm{H}_{2} \mathrm{O} \rightarrow 2 \mathrm{SO}_{4}^{2-}+4 \mathrm{H}^{+}
$$

The Raman spectra for the pyrite (111) plane in Figure 6c exhibit two weak and broad peaks. The first peak is located at $220-234 \mathrm{~cm}^{-1}$, which is possibly due to the mixture of $\mathrm{Fe}(\mathrm{OH})_{3}$ and $\mathrm{S}$ on the pyrite surface. The second peak is located at approximately $280 \mathrm{~cm}^{-1}$, which can be ascribed to $\mathrm{Fe}_{2} \mathrm{O}_{3}$.
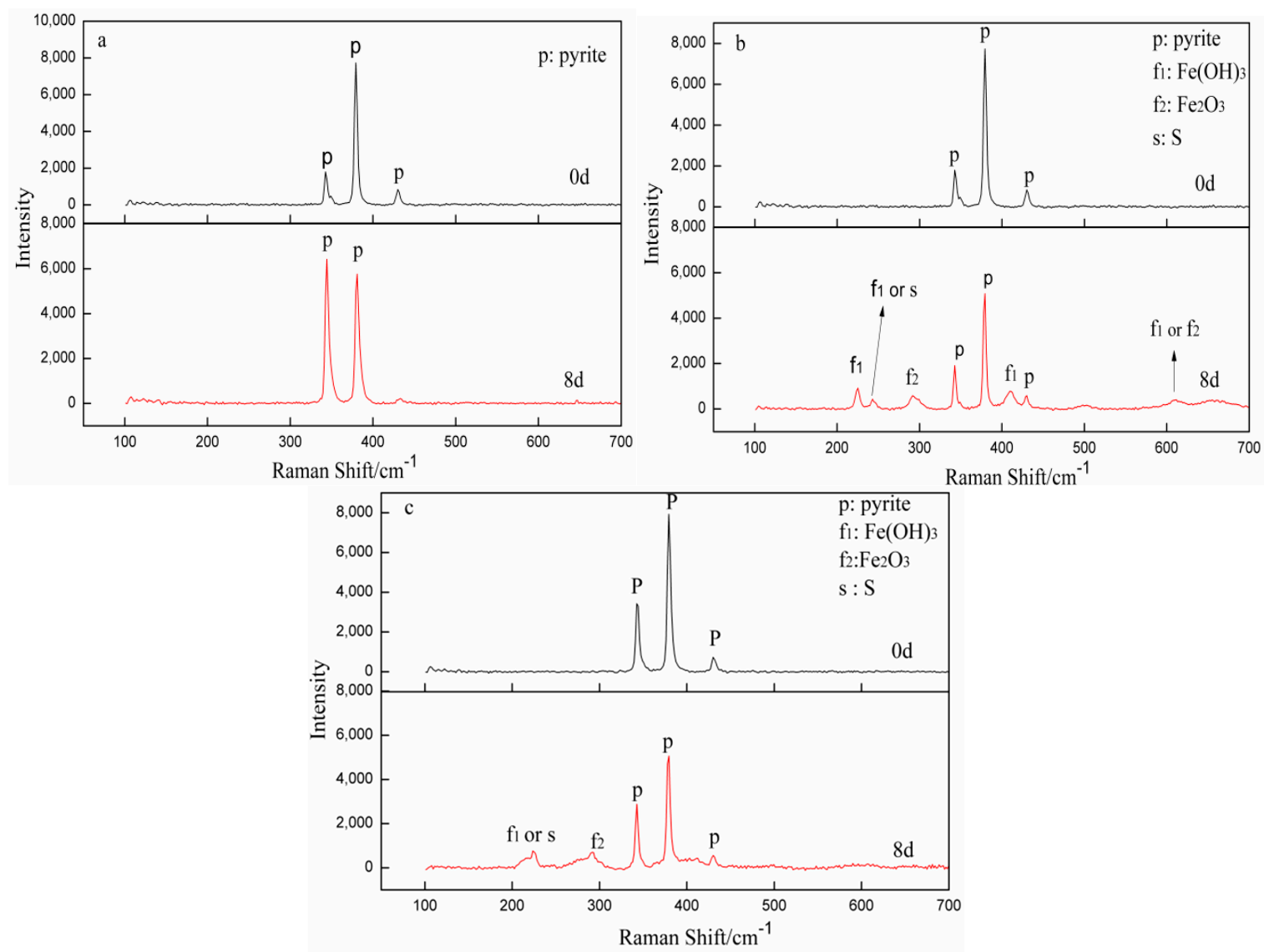

Figure 6. Raman spectrum on the crystal directions of pyrite: (a) (100); (b) (110), and (c) (111).

\subsection{XPS Analysis}

The spectra of pyrite (100), (110), and (111) are shown in Figures 7 and 8. The common binding are determined based on the literature in Table 2. As shown in Figure $7 a$, the $S(2 p)$ peaks of pyrite are concentrated on 162.3,163.4, and $168.5 \mathrm{eV}$. The major peak at $162.3 \mathrm{eV}$ is assigned to the disulfide of lattice pyrite [16,26]. The peak at $163.4 \mathrm{eV}$ is $\mathrm{S}_{8}[7,16]$. The small peak at $168.5 \mathrm{eV}$ is attributed to $\mathrm{Fe}_{2}\left(\mathrm{SO}_{4}\right)_{3}$, which shows that the pyrite surface is slightly oxidized by air. The $\mathrm{Fe}(2 \mathrm{p})$ peaks of pyrite is shown in Figure $7 \mathrm{~b}$. The peaks at $707.2 \mathrm{eV}$ and $720.0 \mathrm{eV}$ are $\mathrm{Fe}\left(2 \mathrm{p}_{3 / 2}\right)$ and $\mathrm{Fe}\left(2 \mathrm{p}_{1 / 2}\right)$ of pyrite $\left(\mathrm{FeS}_{2}\right)$, respectively $[16,26,27]$. The other weak peaks at $710.7,713.2,724.7$, and $732.7 \mathrm{eV}$ belong to $\mathrm{Fe}(\mathrm{OH})_{3}$, $\mathrm{Fe}_{2}\left(\mathrm{SO}_{4}\right)_{3}$, and $\mathrm{Fe}_{2} \mathrm{O}_{3}[16,26]$. The peak at $732.7 \mathrm{eV}$ is the satellite of $\mathrm{Fe}_{2} \mathrm{O}_{3}[26,28]$. The $\mathrm{S}(2 \mathrm{p})$ spectra in Figure $8 \mathrm{a}$ are similar to those of primitive pyrite but with slightly broader peaks. Figure 8a shows the $S(2 p)$ peaks of pyrite (100), (110), and (111) planes after oxidation for eight days. The primary peak with a binding energy of $168.5 \mathrm{eV}$ assigned to $\mathrm{Fe}_{2}\left(\mathrm{SO}_{4}\right)_{3}$ remarkably increases on the (111) plane, 
indicating that the oxidation rate of (111) plane is fast. This finding is consistent with the result of Raman spectra analysis.
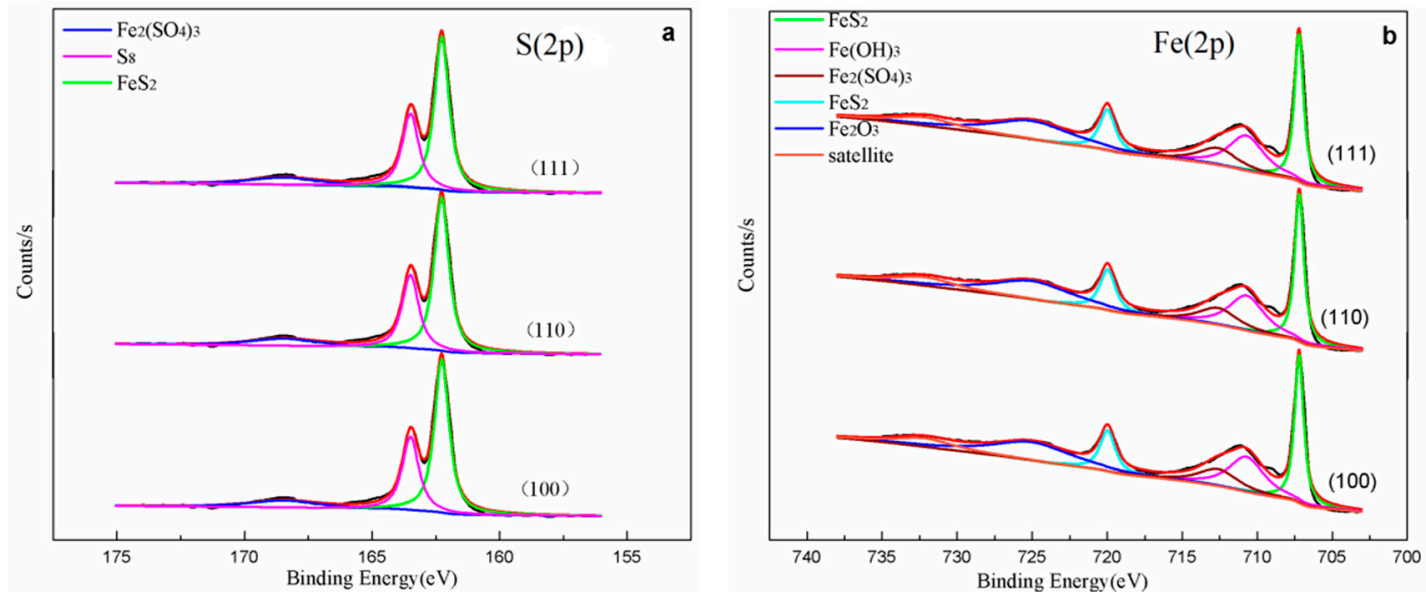

Figure 7. XPS spectra of pyrite (100), (110), and (111): S(2p) (a), and Fe(2p) (b).
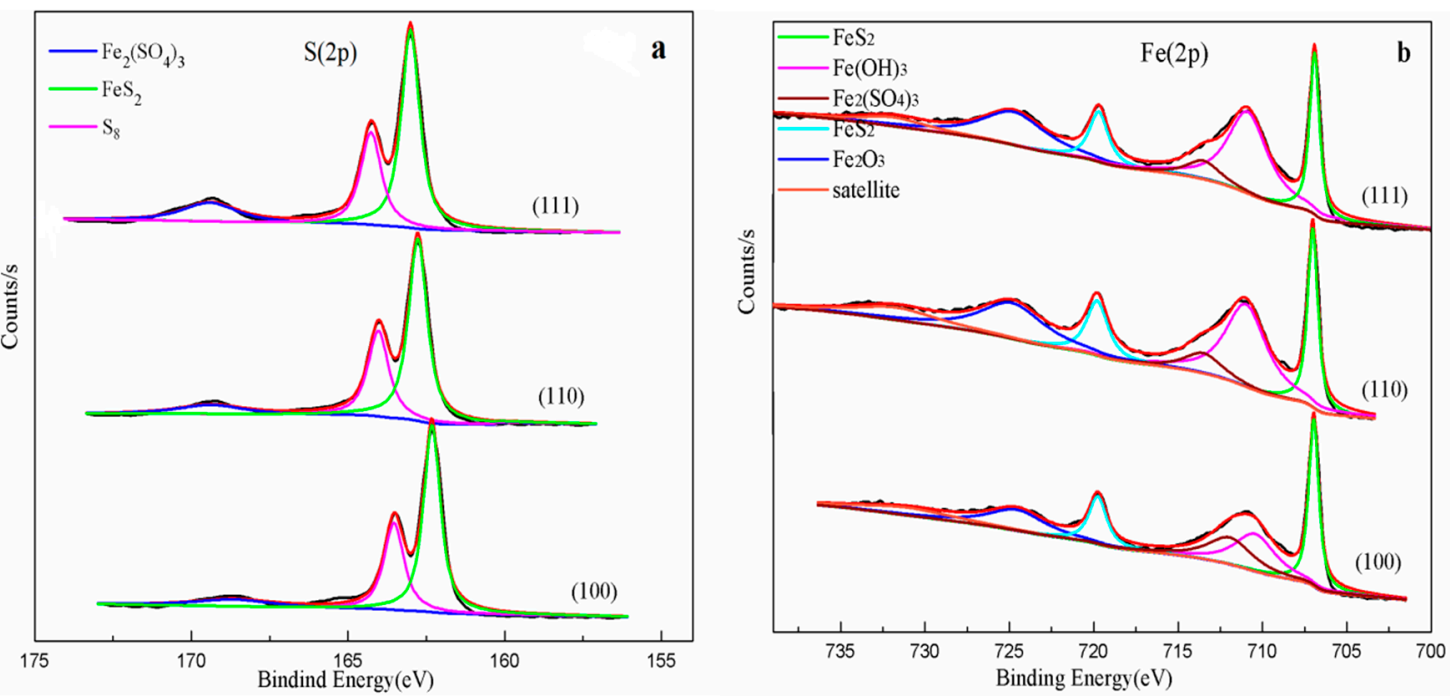

Figure 8. XPS spectra of pyrite (100), (110) and (111) after oxidation for eight days: $S(2 p)(a)$ and $\mathrm{Fe}(2 \mathrm{p})(\mathbf{b})$

Table 2. Binding energy of $\mathrm{Fe}(2 \mathrm{p})$ and $\mathrm{S}(2 \mathrm{p})$ after oxidation for eight days.

\begin{tabular}{cccccc}
\hline \multirow{2}{*}{ Spectrum } & \multirow{2}{*}{$\begin{array}{c}\text { Unreacted } \\
\text { Pyrite }\end{array}$} & \multicolumn{3}{c}{ Binding Energy(eV) (2p) } & Species \\
\cline { 3 - 5 } & & $\mathbf{( 1 0 0 )}$ & $\mathbf{( 1 1 0 )}$ & $\mathbf{( 1 1 1 )}$ & \\
\hline \multirow{2}{*}{$\mathrm{S}_{2 \mathrm{p}}$} & $162.3\left(2 \mathrm{p}_{3 / 2}\right)$ & $162.3\left(2 \mathrm{p}_{3 / 2}\right)$ & $162.3\left(2 \mathrm{p}_{3 / 2}\right)$ & $162.3\left(2 \mathrm{p}_{3 / 2}\right)$ & $\mathrm{FeS}_{2}[16,26]$ \\
& $163.4\left(2 \mathrm{p}_{3 / 2}\right)$ & $163.5\left(2 \mathrm{p}_{3 / 2}\right)$ & $163.5\left(2 \mathrm{p}_{3 / 2}\right)$ & $163.5\left(2 \mathrm{p}_{3 / 2}\right)$ & $\mathrm{S}_{8}[7,16]$ \\
& $168.5\left(2 \mathrm{p}_{3 / 2}\right)$ & $168.6\left(2 \mathrm{p}_{3 / 2}\right)$ & $168.6\left(2 \mathrm{p}_{3 / 2}\right)$ & $168.4\left(2 \mathrm{p}_{3 / 2}\right)$ & $\mathrm{Fe}_{2}\left(\mathrm{SO}_{4}\right)_{3}[16,26]$ \\
\hline \multirow{2}{*}{$\mathrm{Fe}_{2 \mathrm{p}}$} & $707.2\left(2 \mathrm{p}_{3 / 2}\right)$ & $707.0\left(2 \mathrm{p}_{3 / 2}\right)$ & $707.0\left(2 \mathrm{p}_{3 / 2}\right)$ & $706.9\left(2 \mathrm{p}_{3 / 2}\right)$ & \multirow{2}{*}{$\mathrm{FeS}_{2}[16,26,27]$} \\
& $720.0\left(2 \mathrm{p}_{1 / 2}\right)$ & $719.8\left(2 \mathrm{p}_{1 / 2}\right)$ & $720.0\left(2 \mathrm{p}_{1 / 2}\right)$ & $719.7\left(2 \mathrm{p}_{1 / 2}\right)$ & \\
\hline \multirow{3}{*}{ Satellite } & $710.7\left(2 \mathrm{p}_{3 / 2}\right)$ & $710.3\left(2 \mathrm{p}_{3 / 2}\right)$ & $711.1\left(2 \mathrm{p}_{3 / 2}\right)$ & $710.8\left(2 \mathrm{p}_{3 / 2}\right)$ & $\mathrm{Fe}(\mathrm{OH})_{3}[16]$ \\
& $724.7\left(2 \mathrm{p}_{1 / 2}\right)$ & $724.7\left(2 \mathrm{p}_{1 / 2}\right)$ & $724.8\left(2 \mathrm{p}_{1 / 2}\right)$ & $724.7\left(2 \mathrm{p}_{1 / 2}\right)$ & $\mathrm{Fe}_{2} \mathrm{O}_{3}[26,28]$ \\
& $732.7\left(2 \mathrm{p}_{1 / 2}\right)$ & $732.2\left(2 \mathrm{p}_{1 / 2}\right)$ & $732.1\left(2 \mathrm{p}_{1 / 2}\right)$ & $731.8\left(2 \mathrm{p}_{1 / 2}\right)$ & \\
& $713.2\left(2 \mathrm{p}_{3 / 2}\right)$ & $713.2\left(2 \mathrm{p}_{3 / 2}\right)$ & $713.5\left(2 \mathrm{p}_{3 / 2}\right)$ & $713.5\left(2 \mathrm{p}_{3 / 2}\right)$ & $\mathrm{Fe}_{2}\left(\mathrm{SO}_{4}\right)_{3}[26]$ \\
\hline
\end{tabular}

Figure $8 \mathrm{~b}$ shows the $\mathrm{Fe}(2 \mathrm{p})$ peaks of (100), (110), and (111) planes after oxidation for eight days compared with the primitive pyrite. The peak at $710.9 \mathrm{eV}$ is considered to be $\mathrm{Fe}\left(2 \mathrm{p}_{3 / 2}\right)$ of 
$\mathrm{Fe}(\mathrm{OH})_{3}$. The peak at $713.2 \mathrm{eV}$ is the $\mathrm{Fe}\left(2 \mathrm{p}_{3 / 2}\right)$ of $\mathrm{Fe}_{2}\left(\mathrm{SO}_{4}\right)_{3}$. These findings are in agreement with the abovementioned $\mathrm{S}(2 \mathrm{p})$ spectra results. The peak at $724.7 \mathrm{eV}$ is attributed to $\mathrm{Fe}\left(2 \mathrm{p}_{1 / 2}\right)$ of $\mathrm{Fe}_{2} \mathrm{O}_{3}$. The $\mathrm{Fe}\left(2 \mathrm{p}_{1 / 2}\right)$ of $\mathrm{Fe}_{2} \mathrm{O}_{3}$ satellite binding energy is $732.2 \mathrm{eV}$ [26]. The XPS spectra of the (110) and (111) planes are similar. However, the $\mathrm{Fe}\left(2 \mathrm{p}_{3 / 2}\right)$ peak of $\mathrm{FeS}_{2}$ on the (111) plane is weaker than that of (110) and (100) planes. The $\mathrm{Fe}\left(2 \mathrm{p}_{1 / 2}\right)$ peak of $\mathrm{Fe}_{2} \mathrm{O}_{3}$ is obvious on the (111) plane. These conditions verify that the oxidation rate of the (111) plane is faster than that of the (110) plane. Meanwhile, $\mathrm{Fe}(\mathrm{OH})_{3}$ and $\mathrm{Fe}_{2}\left(\mathrm{SO}_{4}\right)_{3}$ are found on the (110) and (111) planes. $\mathrm{Fe}_{2}\left(\mathrm{SO}_{4}\right)_{3}$ was detected based on the XPS spectra, which is different from the Raman spectra.

Based on the Raman spectroscopy and XPS analyses, the following reactions are proposed to have occurred:

$$
\begin{gathered}
\mathrm{FeS}_{2}+3.5 \mathrm{O}_{2}+\mathrm{H}_{2} \mathrm{O} \rightarrow \mathrm{Fe}^{2+}+2 \mathrm{SO}_{4}^{2-}+2 \mathrm{H}^{+} \\
\mathrm{Fe}^{2+}+3 \mathrm{H}_{2} \mathrm{O} \rightarrow \mathrm{Fe}(\mathrm{OH})_{3}+3 \mathrm{H}^{+}+\mathrm{e}^{-} \\
\mathrm{FeS}_{2} \rightarrow \mathrm{Fe}^{2+}+2 \mathrm{~S}^{0}+2 \mathrm{e}^{-} \\
\mathrm{FeS}_{2} \rightarrow \mathrm{Fe}^{3+}+2 \mathrm{~S}^{0}+3 \mathrm{e}^{-} \\
2 \mathrm{Fe}^{3+}+3 \mathrm{H}_{2} \mathrm{O} \rightarrow \mathrm{Fe}_{2} \mathrm{O}_{3}+6 \mathrm{H}^{+}
\end{gathered}
$$

\section{Conclusions}

This work investigated the differences in the directional oxidation rates of pyrite in acid solution, which order is $r_{(111)}>r_{(110)}>r_{(100)}$. The (110) plane appears more reactive than that the (100) plane. These conclusions can be explained by the surface atomic arrangement. The (111) plane is -S-S-S-S- or -Fe-Fe-Fe-Fe-, and the (110) plane is -Fe-S-S-Fe-. Considering that the S-S bond is weaker than the $\mathrm{Fe}-\mathrm{S}$ bond, the (100) plane is more stable. Different etching pits formed on different crystal directions. A square etching pit was formed on the (100) plane. Rectangular and triangular etching pits formed on the (110) and (111) planes, respectively. The different corrosion patterns suggested that the shapes of etching pits were consistent with the symmetry of the crystal direction. Raman spectra and XPS results further indicated that pyrite was oxidized under acid condition to form $\mathrm{Fe}_{2} \mathrm{O}_{3}, \mathrm{Fe}(\mathrm{OH})_{3}, \mathrm{Fe}_{2}\left(\mathrm{SO}_{4}\right)_{3}$, and $S$.

Author Contributions: J.F. and Z.D. proposed and organized the project. J.F., H.T., and Y.H. discussed and designed and performed the experiment. J.F. and H.T. analyzed and interpreted the data. J.F. wrote the main manuscript. Z.D. and Z.Y. revised the main manuscript. All the authors discussed the study.

Funding: This research was funded by the National Key Basic Research Program of China (grant no. 2014CB643401), National Natural Science Foundation of China (grant no. 51404299), and the Hunan Provincial Science and Technology Plan of China (grant no. 2016TP1007).

Conflicts of Interest: The authors declare no conflict of interest.

\section{References}

1. Nesbitt, H.W.; Muir, I.J. X-ray photoelectron spectroscopic study of a pristine pyrite surface reacted with water vapour and air. Geochim. Cosmochim. Acta. 1994, 58, 4667-4679. [CrossRef]

2. Rickard, D. Pyrite: A Natural History of Fool's Gold; Oxford University Press: Oxford, UK, 2015.

3. Tauson, V.L.; Kravtsova, R.G.; Grebenshchikova, V.I.; Lustenberg, E.E.; Lipko, S.V. Surface typochemistry of hydrothermal pyrite: Electron spectroscopic and scanning probe microscopic data. II. Natural pyrite. Geochem. Int. 2009, 47, 231-243. [CrossRef]

4. Abraitis, P.K.; Pattrick, R.A.D.; Vaughan, D.J. Variations in the compositional, textural and electrical properties of natural pyrite: A review. Int. J. Miner. Process. 2004, 74, 41-59. [CrossRef]

5. Sasaki, K.; Tsunekawa, M.; Ohtsuka, T.; Konno, H. Confirmation of a sulfur-rich layer on pyrite after oxidative dissolution by Fe(III) ions around pH 2. Geochim. Cosmochim. Acta 1995, 59, 3155-3158. [CrossRef]

6. Mckibben, M.A.; Barnes, H.L. Oxidation of pyrite in low temperature acidic solutions: Rate laws and surface textures. Geochim. Cosmochim. Acta 1986, 50, 1509-1520. [CrossRef] 
7. Woods, A.N.B. The surface oxidation of pyrite. Appl. Surf. Sci. 1987, 27, 437-452.

8. De Leeuw, N.H.; Parker, S.C.; Sithole, H.M.; Ngoepe, P.E. Modeling the Surface Structure and Reactivity of Pyrite: Introducing a Potential Model for $\mathrm{FeS}_{2}$. J. Phys. Chem. B 2000, 104, 7969-7976. [CrossRef]

9. Hung, A.; Muscat, J.; Yarovsky, I.; Russo, S.P. Density-functional theory studies of pyrite $\mathrm{FeS}_{2}(100)$ and (110) surfaces. Surf. Sci. 2002, 513, 511-524. [CrossRef]

10. Qiu, G.; Gao, T.; Hong, J.; Tan, W.; Liu, F.; Zheng, L. Mechanisms of arsenic-containing pyrite oxidation by aqueous arsenate under anoxic conditions. Geochim. Cosmochim. Acta 2017, 217. [CrossRef]

11. Chandra, A.P.; Gerson, A.R. The mechanisms of pyrite oxidation and leaching: A fundamental perspective. Surf. Sci. Rep. 2010, 65, 293-315. [CrossRef]

12. Long, H.; Dixon, D.G. Pressure oxidation of pyrite in sulfuric acid media: A kinetic study. Hydrometallurgy 2004, 73, 335-349. [CrossRef]

13. Tu, Z.; Guo, C.; Zhang, T.; Lu, G.; Wan, J.; Liao, C.; Dang, Z. Investigation of intermediate sulfur species during pyrite oxidation in the presence and absence of Acidithiobacillus ferrooxidans. Hydrometallurgy 2016, 167, 58-65. [CrossRef]

14. Kelsall, G.H.; Yin, Q.; Vaughan, D.J.; England, K.E.R.; Brandon, N.P. Electrochemical oxidation of pyrite $\left(\mathrm{FeS}_{2}\right)$ in aqueous electrolytes. J. Electroanal. Chem. 1999, 471, 116-125. [CrossRef]

15. Sun, H.; Chen, M.; Zou, L.; Shu, R.; Ruan, R. Study of the kinetics of pyrite oxidation under controlled redox potential. Hydrometallurgy 2015, 155, 13-19. [CrossRef]

16. Tu, Z.; Wan, J.; Guo, C.; Fan, C.; Zhang, T.; Lu, G.; Reinfelder, J.R.; Dang, Z. Electrochemical oxidation of pyrite in pH 2 electrolyte. Electrochim. Acta 2017, 239, 25-35. [CrossRef]

17. Paszkowicz, W.; Leiro, J.A. Rietveld refinement study of pyrite crystals. J. Alloys Compd. 2005, 401, $289-295$. [CrossRef]

18. Vaughan, D.J.; Craig, J.R. Mineral Chemistry of Metal Sulfides; Cambridge University Press: Cambridge, UK, 1987; pp. 410-411.

19. Chen, G.Y.; Sun, D.S.; Zhang, L.; Zang, W.S.; Wang, J.; Lu, A.H. Morphogenesis of pyrite. Geoscience 1987, 1, 60-76.

20. Sit, P.H.; Cohen, M.H.; Selloni, A. Interaction of Oxygen and Water with the (100) Surface of Pyrite: Mechanism of Sulfur Oxidation. J. Phys. Chem. Lett. 2012, 3, 2409-2414. [CrossRef]

21. Zhu, J.; Xian, H.; Lin, X.; Tang, H.; Du, R.; Yang, Y.; Zhu, R.; Liang, X.; Wei, J.; Teng, H.H. Surface structure-dependent pyrite oxidation in relatively dry and moist air: Implications for the reaction mechanism and sulfur evolution. Geochim. Cosmochim. Acta 2018, 228, 259-274. [CrossRef]

22. Ndlovu, S.; Monhemius, A.J. The influence of crystal orientation on the bacterial dissolution of pyrite. Hydrometallurgy 2005, 78, 187-197. [CrossRef]

23. Zhao, S.; Xu, C.; Zhang, G.; Li, K. Etch Figures Related to the Symmetry and Structure of the Crystal Faces. Earth Sci. 2013, 38, 211-217.

24. Nesbitt, H.W.; Bancroft, G.M.; Pratt, A.R.; Scaini, M.J. Sulfur and iron surface states on fractured pyrite surfaces. Am. Mineral. 1998, 83, 1067-1076. [CrossRef]

25. Wang, W.; Wang, J.; Zhao, S. Crystal Morphology; China University of Geosciences Press: Wuhan, China, 2001.

26. Descostes, M.; Mercier, F.; Thromat, N.; Beaucaire, C.; Gautier-Soyer, M. Use of XPS in the determination of chemical environment and oxidation state of iron and sulfur samples: constitution of a data basis in binding energies for Fe and $\mathrm{S}$ reference compounds and applications to the evidence of surface species of an oxidized pyrite in a carbonate medium. Appl. Surf. Sci. 2000, 165, 288-302.

27. Eggleston, C.M.; Ehrhardt, J.J.; Stumm, W. Surface structural controls on pyrite oxidation kinetics; an XPS-UPS, STM, and modeling study. Am. Mineral. 1996, 81, 1036-1056. [CrossRef]

28. Sang, Y.L.; Kim, D.H.; Choi, S.C.; Lee, D.J.; Ji, Y.C.; Kim, H.D. Porous multi-walled carbon nanotubes by using catalytic oxidation via transition metal oxide. Microporous Mesoporous Mater. 2014, 194, 46-51.

(C) 2018 by the authors. Licensee MDPI, Basel, Switzerland. This article is an open access article distributed under the terms and conditions of the Creative Commons Attribution (CC BY) license (http:/ / creativecommons.org/licenses/by/4.0/). 